\title{
NEW LEADERS FOR TECHNOLOGICAL BREAKTHROUGHS IN THE ENERGY INDUSTRY
}

\author{
LAZAR GITELMAN \& MIKHAIL KOZHEVNIKOV \\ Department of Energy and Industrial Management Systems, Ural Federal University, Russia
}

\begin{abstract}
The article presents a program that makes it possible to integrate and coordinate the efforts of the "science - education - business" triad in order to address emerging tasks that the energy industry is facing amid radical technology modernization and smartization of the energy sector. The authors propose a multi-project called "New leaders for sustainable energy and the industry of the future" that consists of three sections: 1) Energy Business Striving for Leadership, 2) University for Anticipatory Education and 3) Integrated Research-Intensive Consulting. It is shown that the implementation of the multi-project calls for establishing a so-called "smart partnership" among the parts of the triad. The partnership is based on a long-term research agenda, unified methodology that builds upon the principles of system of systems management, and a technological platform. The backbone of the multiproject is Anticipatory Management in Fast-Growing Industries - a research field that the authors are working on. It sets the logic for building a portfolio of promising studies. The article outlines the experience and the first outcomes of implementing the proposed initiatives at Ural Federal University. Keywords: sustainable energy, multi-project, technology modernization, industry of the future, smart partnership, anticipatory learning, anticipatory management, technological platform, researchintensive consulting, energy business.
\end{abstract}

\section{INTRODUCTION}

A new generation of managers in the power industry will en masse participate in a technological breakthrough due to:

- the adoption of cutting-edge energy technologies;

- smartiziation of energy production;

- the spread of a new industrial revolution - Industry 4.0 - in energy consuming system. This will determine a fundamentally different configuration of energy markets and existing energy facilities undergoing an overhaul.

That will happen amid a faster pace of change, growing instability, including in geopolitics, a snowballing number of complex and ill-structured problems, the solution of which requires new knowledge and a large number of databases. The key changes will be associated with the deployment of intelligent energy systems, cybersecurity systems, reliability and sustainability of power supply, energy saving technologies, distributed generation, and a variety of economic instruments for consumer relationship management [1]-[5].

Major technological innovations, tools for remote control of energy infrastructure (power and heat grids) start off profound organizational transformations and a radical shift in the principles of operational maintenance of and repairs to energy facilities. There will be a sharp decrease in response time to problems that cannot be solved by relaying on prior experience. Prior experience in its conventional interpretation will be losing its value, whereas flexible thinking, one's mode of conduct in emergency situations, leadership skills, and methodological culture will come to the forefront.

There will soon be a sharp increase in demand for professions capable of: 
- designing organizational and economic systems with innovative characteristics (regulatory mechanisms for energy markets, prices, investment; governance systems for regional energy industries; methods of utilities' interaction with customers);

- developing strategies and anticipatory management tools, including risk minimization;

- performing comprehensive and long-term forecasting and foresight research, including trend analysis and long-term goal setting, identification of challenges and external threats and impact assessment;

- conducting analytical reviews of global markets for industrial technology, capital, knowledge and competencies;

- selecting innovations in global markets and adjusting them to the deployment location taking into consideration regionally specific conditions of the energy industry.

Managers will need new competencies such as:

Understanding the context and trends in energy consuming systems:

- a holistic vision of processes and factors that determine the emergence, development and behavior of complex systems;

- managerial decision making with attention to interdisciplinary links between technology, reliability and security of the economy and business results;

- quick adaptation to a changing situation in its initial phase;

- $\quad$ working in interdisciplinary teams, including international experts;

- access to essential knowledge bases, rapid analysis and summary;

- $\quad$ organization of an active innovation process at all management levels [6-9].

Global challenges and threats, uncertainty and the aggressive nature of the external environment, the inert character of the industry and disastrous impacts of blackouts highlight the importance of preemptive management measures and create a new paradigm for development management. The question is in fact about building a fundamentally new model of development management both in the electric power industry and ancillary sectors of the economy, including energy consumers, suppliers of primary energy sources, energy equipment, investors and, of course, skilled workforce. Within the paradigm, the introduction of threat prevention and opportunity identification systems and the development of anticipatory management competencies in managers lie at the core of the agenda [10]-[12]. That will of course call for arrangements facilitating anticipatory learning and, therefore, a radial transformation of educational models, both in terms of content and teaching methods.

\section{FEATURES OF EXTERNAL CHALLENGES TO THE ELECTRIC POWER INDUSTRY}

In this article, the authors use the following definitions.

Challenges are new conditions and factors of the external environment that require appropriate managerial decisions. They can uncover new resources for development and better efficiency of the electric power industry, or transform into threats.

Threats are factors that are rooted in challenges and can destabilize the energy market if the conditions are right, disrupt the regular operation of an energy system, or slow down the development of the industry. Potential threats can occur if they are ignored in the course of managerial decision making, or in the case of inadequate structural, technological, 
organizational and economic policies being implemented by the industry's governance bodies and by energy companies.

For the purposes of analysis it is convenient to identify two orbits in the external environment: the "near" orbit (energy) and the "far" orbit (multi-factor). The first orbit includes elements that have direct links to participants in the electric power industry (supplies of equipment and fuel, electricity consumers). The factors of the second orbit (overall economic conditions, science and technology, climate, environmental protection) have an indirect impact on the industry, sometimes with a considerable time lag. Nonetheless, its ultimate influence can be rather strong and finding adequate managerial solutions can prove a hard task.

The specific feature of the electric power industry as a target for challenges and threats is that its external environment consists of two orbits that each contain a certain combination of factors, potential threats and their possible impacts.

The challenges occur periodically under the influence of fairly strong financial, economic, scientific, technological, resource and fuel- related and climatic factors (shifts). The challenges generate both negative phenomena (threats) within the industry, and open new opportunities and development trends:

- financial and economic crises reduce demand for electricity in the economic and cause a massive investment outflow, which slows down the technological development of the electric power industry and leads to a critical level of wear and tear in energy facilities;

- reassessment of subsoil fuel reserves and changes to the sales territory could require a revision of the entire structural policy of the industry;

- $\quad$ steady climate change both reduces and expands the possibility of renewable energy sources.

Table 1 outlines some of the challenges that typically faced by the electric power industry and their implications manifested by threats.

Scientific breakthroughs in the field of energy technology that have turned into commercial innovations have the potential of drastically improving the functional qualities and public effectiveness of the electric power industry. All too often, though, they require a serious transformation of management, large-scale retrofitting of power supply systems, changes to operation dispatch control and the introduction of new models of the competitive electricity and capacity market. In this context, we can mention growing penetration of RES in the structure of generating capacity in many countries, the creation of renewable energy storage solutions, development of distributed (small-scale) generation, intelligent grids, small and medium nuclear power units with intrinsically safe reactors.

The above-mentioned features confirm the principle difference of external challenges to the electric power industry as a key branch of the economy. We are talking about different local changes to the production and economic micro-environment of individual energy companies that generate certain threats to their competitive edge and financial stability and necessitate creating a system of anticipatory management within the company to neutralize them.

\section{NEW RESEARCH AREA}

The preliminary analysis alone shows that solving the major, complex and poorly structured task of organizing anticipatory management will require a large volume of new knowledge from various fields. That brings to the foreground a new area of research that the authors are nurturing - "Anticipatory Management in Fast-Growing Industries". According to the 
Table 1: Challenges and threats that determine strategic changes in the global electric power industry (examples).

\begin{tabular}{|c|c|}
\hline Challenge & Threat \\
\hline $\begin{array}{l}\text { Rapid smartization of the } \\
\text { energy sector and its } \\
\text { integration with other } \\
\text { infrastructure sectors of the } \\
\text { economy through "smart" } \\
\text { technology }\end{array}$ & $\begin{array}{l}\text { - The energy sector (both at the level of industry and individual companies) } \\
\text { is not ready to embrace cutting-edge technologies } \\
\text { - Variable load operation of power plants and grids, higher technical losses in } \\
\text { distribution systems, which leads to higher costs along the entire chain of } \\
\text { power supply and has a negative impact on the reliability of power supply } \\
\text { - Growing electricity prices due, the need to implement large-scale } \\
\text { investment projects } \\
\text { - The industry develops in asymmetry with demands of pro-active } \\
\text { consumers }\end{array}$ \\
\hline $\begin{array}{l}\text { Higher share of hard-to- } \\
\text { recover hydrocarbons (shale } \\
\text { oil, LNG, offshore } \\
\text { hydrocarbons) in the fuel } \\
\text { balance of combined heat } \\
\text { and power plants }\end{array}$ & $\begin{array}{l}\text { - Higher cost of production of electric power at affected heat and power } \\
\text { plants } \\
\text { - Lower profitability of energy companies } \\
\text { - Growing energy prices } \\
\text { - Need for additional investment in overhaul of boiler units }\end{array}$ \\
\hline $\begin{array}{l}\text { Accelerated development of } \\
\text { RES in response to } \\
\text { environmental requirements } \\
\text { of the public }\end{array}$ & $\begin{array}{l}\text { - Unfavorable share of RES in the structure of power generating } \\
\text { capacity that requires regular unloading (stoppage) of highly efficient } \\
\text { CHPs and even NPPs } \\
\text { - Deformation of electricity market and lower effectiveness of its price sig }\end{array}$ \\
\hline $\begin{array}{l}\text { Decreasing share of } \\
\text { manufacturing in electricity } \\
\text { consumption }\end{array}$ & $\begin{array}{l}\text { - Uneven load schedule of energy systems } \\
\text { - Higher cost of production at power plants } \\
\text { - Need for additional investment in peaking capacity } \\
\text { - Problems of introducing optimal daily operation schedule at NPPs and } \\
\text { large coal fired CHPs }\end{array}$ \\
\hline $\begin{array}{l}\begin{array}{l}\text { Decreasing demand in } \\
\text { wholesale electricity and } \\
\text { capacity market }\end{array}\end{array}$ & $\begin{array}{l}\text { - Likelihood of losing part of generating capacity and power plant } \\
\text { personnel when excess least efficient capacity is taken out of service } \\
\text { without possibility of retrofitting } \\
\text { - If the installation remains in service, consumers sustain higher losses } \\
\text { due to excessive prices on the wholesale market and motivation for } \\
\text { going off-grid }\end{array}$ \\
\hline $\begin{array}{l}\text { Reliability ("fail-safety") of } \\
\text { energy equipment has } \\
\text { entered the system of market } \\
\text { relations and become an } \\
\text { economic category }\end{array}$ & $\begin{array}{l}\text { - Periodical failures of energy equipment (with massive occurrence in } \\
\text { the worst-case scenario!) due to a drive to cut maintenance costs }\end{array}$ \\
\hline
\end{tabular}

authors, the goal of the new research area is to create a methodology and a knowledge base for anticipatory management in the light of technology modernization and emergence of a new industry. The scope of research is the conditions, tools and competencies for anticipatory management and leadership.

Within the research, the authors intend to solve the following tasks:

1. describe a promising management model that is based on timely detection of threats and opportunities;

2. build a methodology of identifying key trends in the global environment that determine the future industrial landscape and competencies;

3. create a method of designing the future that ensures the precise targeting of anticipatory measures; 
4. substantiate the principles of anticipatory learning and the new generation of educational programs that forge competencies for solving ultra-complex tasks.

Original hypothesis. The practical need for anticipatory management can be satisfied by creating a system of early detection of threats and emerging opportunities and anticipatory knowledge and competencies. This organizational system can function and develop under the conditions of the constant expansion, extension and replenishment of knowledge about emerging trends in the global environment, assessment of the trends' potential for growth and actualization in scientific and technological innovations.

A breakthrough is needed to develop and introduce a unique system as quickly as possible that would make it possible to foresee scientific, technological, socio-economic and organization novelties with specific probabilistic properties and to nurture competencies in managers and engineers that would enable them to act preemptively. To achieve that, radical changes need to be implemented in the work of universities.

Fundamentally, the problem cannot be solved without targeted scholarly studies aimed at forecasting advances in technology and trends in socio-economic development, building a vision of the future and integrating this activity with education and innovation. That gives the lead and definitive role to science and its relationships with education and business as part of a holistic system aims to stay constantly ready for change [13]-[15]. The fact that makes the system unique is that it combines the interests and intellectual resources of the "science - education - business" triad into a single project with common goals. That could be done through:

- forming a shared research agenda that fits the needs of all parties involved;

- paying constant attention to the newest technological advances, industry-specific and interdisciplinary technologies from the point of view of their possible application in production;

- $\quad$ anticipatory learning that arms managers with new knowledge and competencies;

- effective communication in a complex environment of uncertainty and knowledge growth;

- mechanisms for enhancing the process of innovation and its synchronization with the development of human resources and intellectual capital.

Concept. The research area focuses on interdisciplinary competences for managing complex systems in the context of a new industry and technological modernization. The authors' concept is based upon the following principles.

1. Anticipatory management is aimed at preventing challenges and threats generated by external instability (by using the results of content analysis of global, national and regional environments) and at detecting emerging opportunities as a result of the monitoring of technological trends, using weak signals and structuring complex priorities. The purpose of anticipatory management is preparing management to unexpected change and planned innovation (five to ten to 15 years in advance). The preparation includes R\&D efforts, personnel development, the introduction of flexible organization structures that actively communicate with customers, and the establishment of a flexible corporate environment.

2. An important factor of building competencies for anticipatory management is continuous professional education with elements of anticipatory learning that seeks to provide learners with up-to-date knowledge based on research into promising trends in science and technology. 
3. Anticipatory learning arrangements require radical reforms at universities, a stronger research component of the educational process being the primary objective. The focus of anticipatory learning is on the principles and methods of designing the future: foresight studies, forward-looking vision, strategies of leadership, development of new socio-technological, organizational and environmental systems.

4. The methodology of systems engineering and interdisciplinary competences (being able to anticipate the future, engineering and management and engineering and economic competencies in the first place) acquire universal and fundamental importance to managers, engineers, and economists working in one team. The authors provided a detailed description of and argument for the competences in [16], [17]. A general description is given in Fig. 1.

Within the context of this research area, the authors accept the following sectors of the economy and the industries as prototypes driving the technological breakthrough and economic growth:

- universities that ensure the generation and transfer of new knowledge and provide training to a new generation of personnel with required competencies;

- the electric power industry that supplies the economy with electricity, the key source of energy for modern high-performance technologies of Industry 4.0. The latter is already a showcase Smart Grid solutions;

- research-intensive services, including engineering and consulting that acts as the integrator of cutting-edge market solutions at the interface of sector-specific and pan-sector activities.
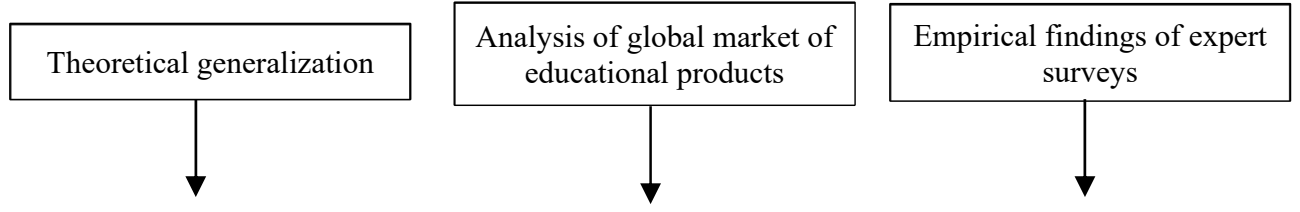
MULTIPLE INCREASE IN SIGNIFICANCE OF SPECIFIC COMPETENCIES REQUIRED
FOR TECHNOLOGICAL BREAKTHROUGH

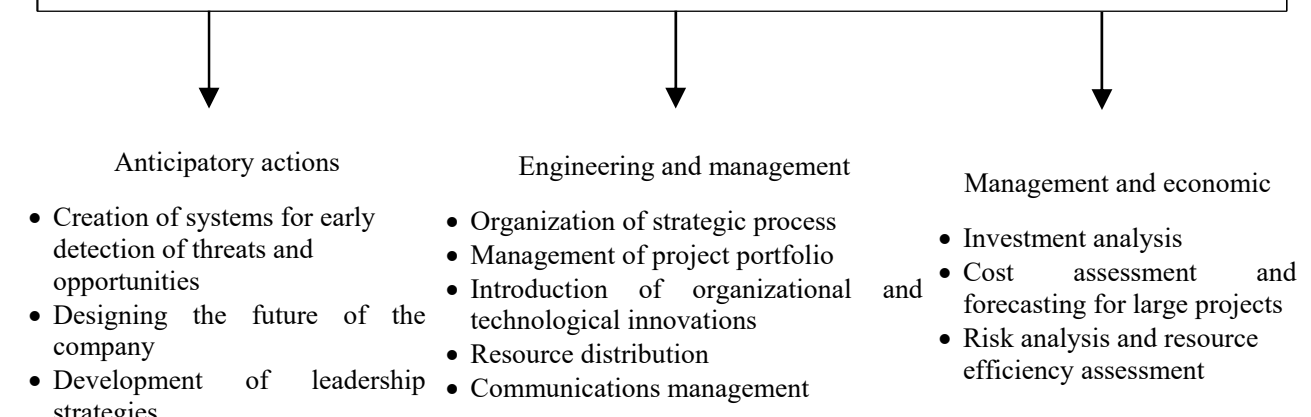

Figure 1: Focus of research area: new competencies. 


\section{INNOVATIVE PROGRAM EMPLOYING NEW KNOWLEDGE}

The research area described above serves as the foundation and a constituent part of the innovative program "New Leaders for Technological Modernization and Industry of the Future" that is implemented by the research and educational center for interdisciplinary studies in engineering and economics and educational projects (REC "INZHEK") at Ural Federal University. A snapshot of the program can be found in Fig. 2.

The main idea of the program is to create a mechanism for continuous interaction between science, education and business for the purpose of developing and implementing large technology modernization projects in industry and for training a new generation of workforce. The smart partnership is a complex system that exhibits such typical characteristics as interdependence, self-organization, adaptability, continuous interaction with the external environment and prediction of change in the external orbit, verification of decisions, a large volume of feedback in processes (Fig. 3). The complex system cannot be governed with traditional tools; its evolution will only take place if the interests of all agents involved in the partnership system are synchronized and if a unified operating methodology is used (the innovative program utilizes the ISKO methodology designed by the authors [17]). The main areas of focus for the program: technology modernization and breakthrough - new industry - high technology - interdisciplinarity - new competencies - anticipatory management - strategic leadership - new generation of educational programs.

The portfolio of studies includes 12 interconnected interdisciplinary projects that are all aimed at achieving tangible results of research works being implemented, consulting and educational products, methods and technologies for anticipatory learning that have been trialed and discussed with the academic community and experts. Table 2 contains the characteristics of some of them.

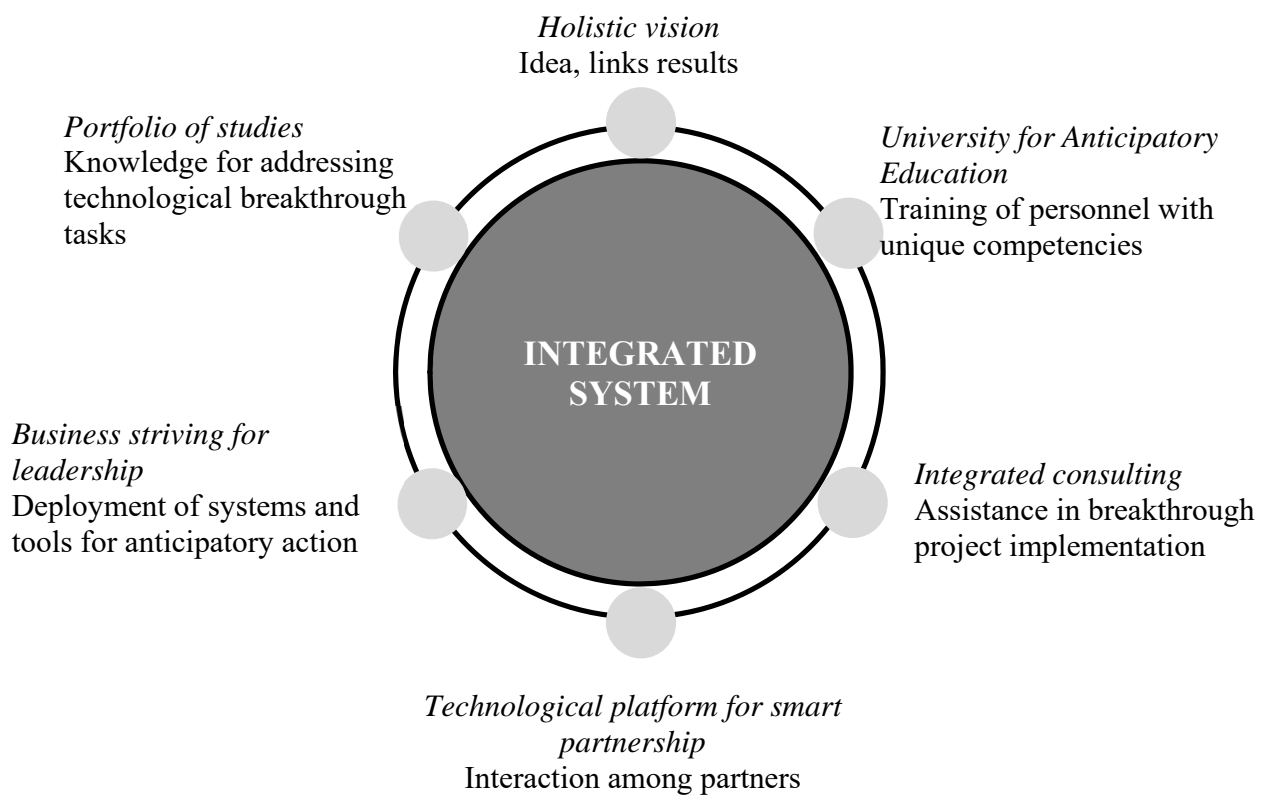

Figure 2: Kew components of innovative program "New Leaders". 


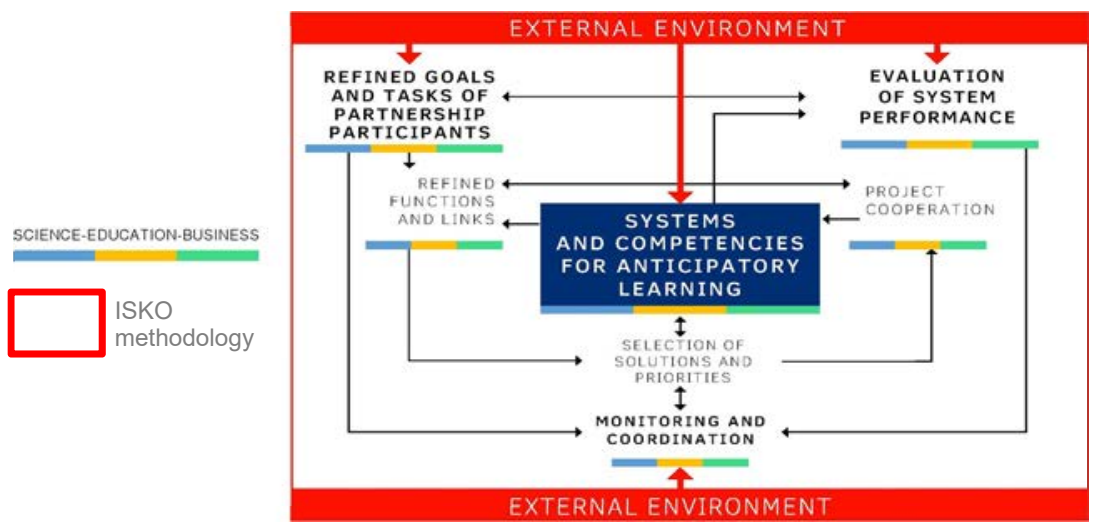

Figure 3: Integrated system of smart partnership: systems of system management.

Table 2: A fragment of the project portfolio.

\begin{tabular}{|c|c|c|}
\hline Project & Purpose & Objectives \\
\hline $\begin{array}{l}\text { "Promising } \\
\text { sector-specific } \\
\text { technologies, } \\
\text { markets, } \\
\text { strategies" }\end{array}$ & $\begin{array}{l}\text { Hypothesis about } \\
\text { development drivers } \\
\text { and key } \\
\text { modernization } \\
\text { solutions }\end{array}$ & $\begin{array}{l}\text { - Define specific content features of technology } \\
\text { modernization tasks } \\
\text { - Identify trends in market and technology } \\
\text { transformation } \\
\text { - Substantiate the content and priority of } \\
\text { leadership strategy }\end{array}$ \\
\hline $\begin{array}{l}\text { "Personnel for } \\
\text { anticipatory } \\
\text { management" }\end{array}$ & $\begin{array}{l}\text { To train specialists } \\
\text { who are capable of } \\
\text { anticipatory action } \\
\text { amid high uncertainty } \\
\text { and abundance of } \\
\text { new knowledge }\end{array}$ & $\begin{array}{l}\text { - Design a combination and technology of } \\
\text { building anticipatory action competencies } \\
\text { - Design instruments for selection and development } \\
\text { of engineers and managers capable of innovation. } \\
\text { - Define conditions that encourage professional } \\
\text { development of managers }\end{array}$ \\
\hline $\begin{array}{l}\text { "Design of } \\
\text { interdisciplinary } \\
\text { educational } \\
\text { programs" }\end{array}$ & $\begin{array}{l}\text { Principles of building } \\
\text { educational programs } \\
\text { while taking into } \\
\text { account links between } \\
\text { engineering, } \\
\text { management, } \\
\text { innovation and } \\
\text { environment }\end{array}$ & $\begin{array}{l}\text { - Select branches of science and practices that } \\
\text { determine promising managerial and } \\
\text { engineering solutions } \\
\text { - Define characteristics and properties of } \\
\text { interdisciplinary educational programs } \\
\text { - Determine interdisciplinary content while } \\
\text { taking into account the need for anticipatory } \\
\text { management }\end{array}$ \\
\hline $\begin{array}{l}\text { "Business } \\
\text { School 2.0" }\end{array}$ & $\begin{array}{l}\text { A model of business } \\
\text { education for training } \\
\text { top managers and } \\
\text { teams with } \\
\text { anticipatory action }\end{array}$ & $\begin{array}{l}\text { - Marketing of interdisciplinary educational } \\
\text { programs } \\
\text { - Incorporate project-related studies into the } \\
\text { learning process and engage students in } \\
\text { research } \\
\text { - Create a unique environment for personal } \\
\text { development of leaders and formation of } \\
\text { breakthrough teams }\end{array}$ \\
\hline
\end{tabular}


The concept of anticipatory learning implies the use of the task-oriented approach.

1. The subjects being considered are technical, organizational and economic and environmental problems of the electric power industry to which no unequivocal solution has been given yet (e.g. thermonuclear fusion or MHD generation). Existing proposals as to further directions of research are analyzed to decide on their pros and cons and worthiness.

2. Existing views on the future of the development of the electric power industry (over a 20-30 year outlook period) are analyzed with the use of scientific and technical methods of forecasting.

3. Economic conditions are defined for commercial use of existing scientific and technological developments as a basis for promising innovations in the industry.

The system of anticipatory learning builds upon a range of techniques (professionalism building conveyor, intellectual business games, mentorship and internal coaching), with a socalled leadership incubator having a particular significance. It is a specially designed environment that creates conditions for nurturing promising highly skilled personnel and teams that are capable of keeping a business or an organization competitive amid uncertainty (Fig. 4).

Integrated consulting for anticipatory development (ICAD) is a method, structure and business of providing ultra-complex highly professional services on the basis of a systemic complex of knowledge and methodology for solving future tasks [24]. The complex accumulates findings of research into trends and scientific and technological advances in the global environment, anticipatory learning programs, methods of organizing collective knowledge and innovation generation in ancillary fields (management, engineering, IT, social and cultural, socio-technological) (Fig. 5). An important prerequisite and condition for ICAD is a networking model of cooperation among regional, national and international experts who come together in one team to solve a task.

The innovative program enables the authors to:

- $\quad$ start training a breakthrough team for technology modernization and organizational transformation in the biggest private energy company of Russia, Public joint-stock company "T Plus";

- introduce a new model of anticipatory management at energy companies of the Urals (Fig. 6);

- build a portfolio and learning content for interdisciplinary programs of anticipatory learning.

The list of examples includes bachelor's and master's degree programs "Management in the Energy Sector and High-Tech Industries", "Leadership in Engineering, Management and IT Business", "Strategic Management in the Energy Sector", "Global Energy Business", and a number of customized corporate programs of continuous learning. To serve the needs of the program, a specialized technological platform for smart partnership and a communications network is being developed that includes leading Russian and foreign universities, research centers, in-house training centers at major energy companies), with RES "INZHEK" acting as the networking coordinator; considerably intensify research efforts, having more than doubled the number of published works over the past year. 


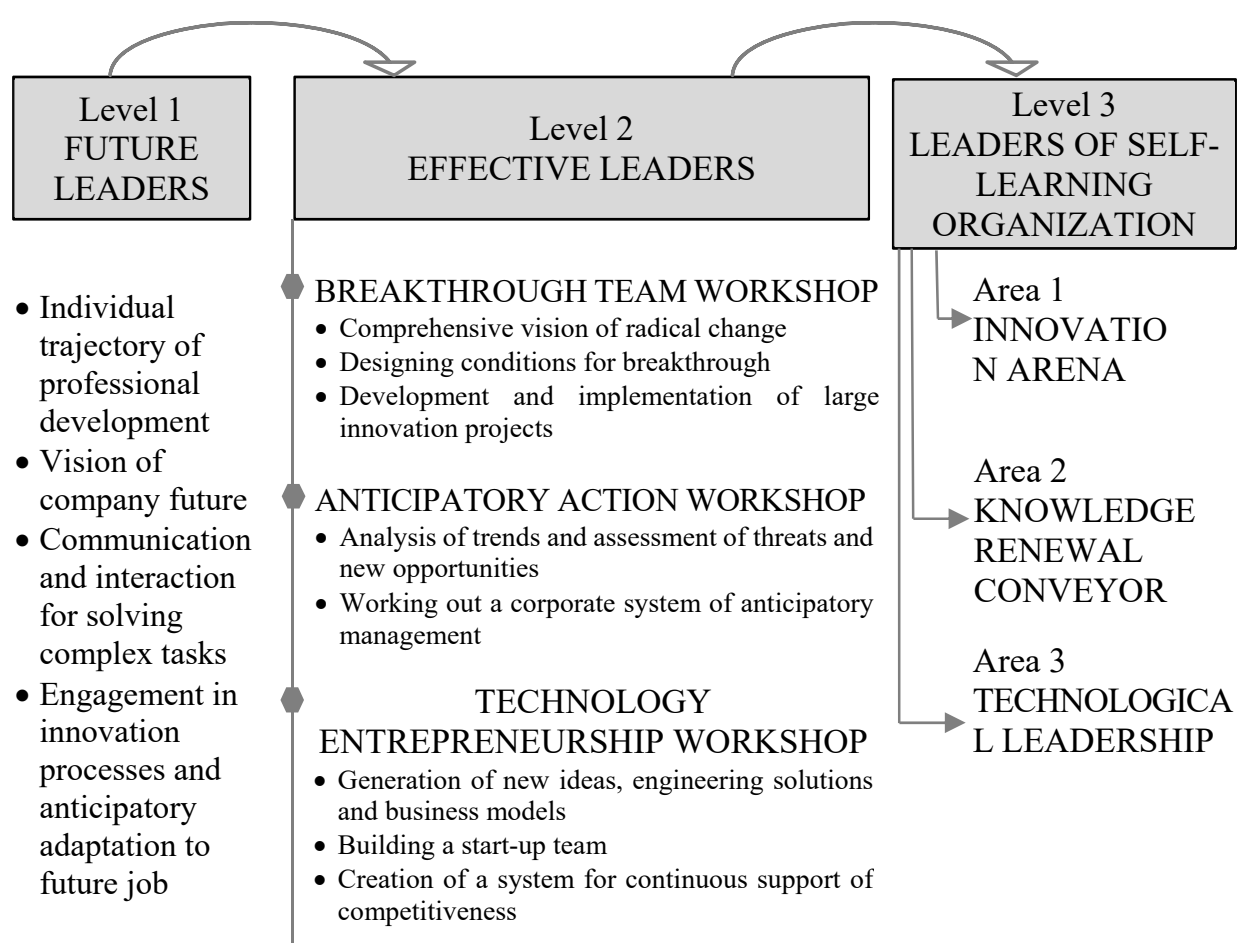

Figure 4: Structure of leadership incubator.

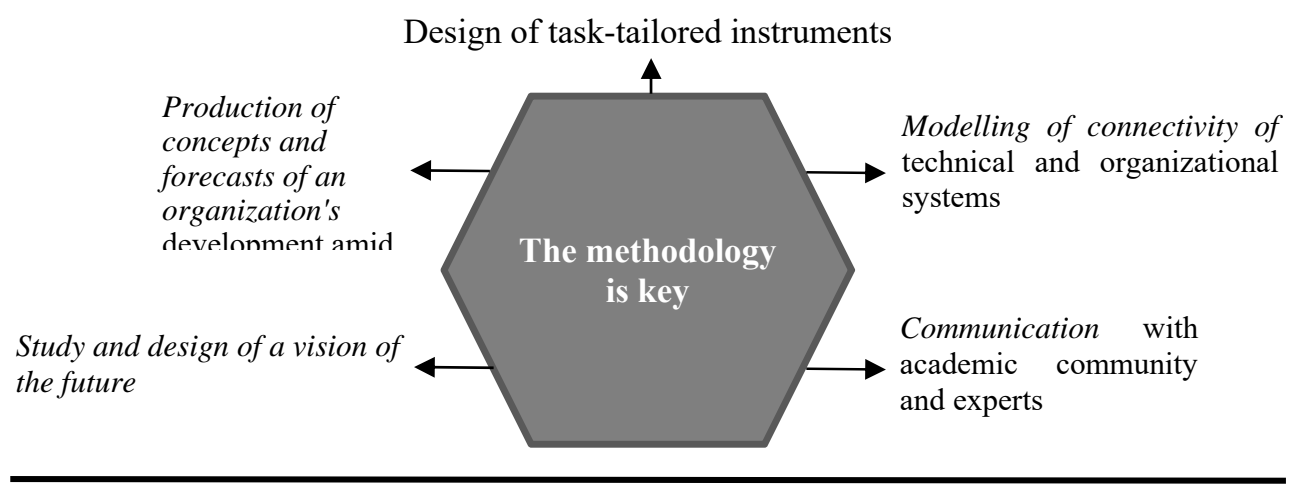

Resolving conflict between the need to expand the range of methodologies and their customization.

Figure 5: Core competencies of integrated consulting. 


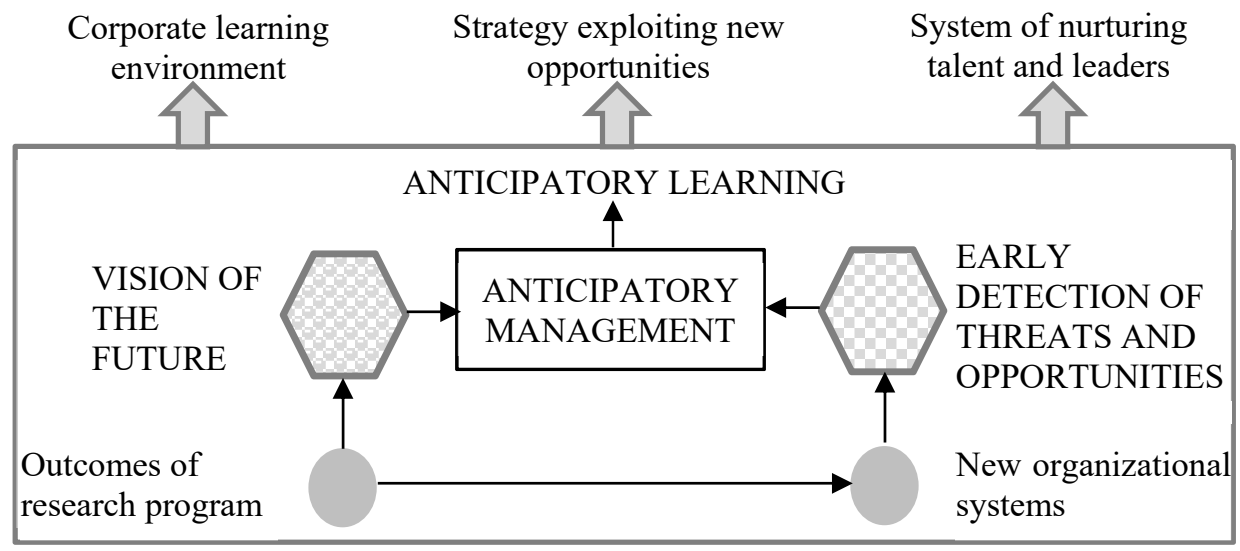

Figure 6: New model of management proposed for introduction at energy companies.

\section{CONCLUSION}

As a summary, it seems appropriate to highlight the following facts that served as the premise for the described accomplishments.

1. A stream of technologies that employ the latest scientific and technological advances in the global environment is shaping new values of young people, new markets of goods, services and entertainment and are creating a completely new industrial landscape, management systems and business models. This is happening so fast that sustainable development can only be guaranteed to organizations that will be the first to foresee the new look of their industry, consumers and future competencies.

2. The challenges that the electric power industry faces today undoubtedly highlight the need for anticipatory management and - therefore - for a switch to anticipatory learning. That sets a difficult task for both energy companies and universities: they need to convert to a new model of management as quickly as possible and as effectively as possible.

3. Foreseeing the future with the required degree of detail and, most importantly, quick preparation to its arrival will require so much new domain and interdisciplinary knowledge, diverse information and unconventional solutions, that no person or organization taking management development decisions (governments, business, universities, scientific organizations) will be able to solve such a big and complicated problem singlehandedly. This is only possible when the intellectual resources of the smart partnership of "science - education - business" are pulled together for the sake of the common goal.

4. The combination of specialized research products offered as part of the innovative program "New Leaders for Technology Modernization and Industry of the Future" will make it possible to create a scientific platform and introduce in each party involved in the smart partnership a new paradigm of development management and anticipatory learning that is aimed at nurturing competencies for anticipatory action.

ACKNOWLEDGEMENT

The work was supported by Act 211 of the Government of the Russian Federation, contract № 02.A03.21.0006. 


\section{REFERENCES}

[1] Gudmestad, O.T. \& Traa, K., Sustainable use and production of energy in the 21st Century, International Journal of Energy Production and Management, 1(1), 2016, pp. $1-15$.

[2] Kühna, M., Ask, M., Bruckman, V., Hangx, S. \& Juhlin, C., Sustainable supply of resources and energy is a challenge, Energy Procedia, 76, pp. 1-5, 2015.

[3] Jarlsby, E., The global energy challenge: Still fuel for progress? International Journal of Energy Production and Management, 1(1), 2016, pp. 33-49.

[4] Genon, G., Panepinto, D. \& Viggiano, F., Sustainability in energy production. International Journal of Energy Production and Management, 1(1), pp. 16-32, 2016.

[5] Armor, J.N., Key questions, approaches, and challenges to energy today, Catalysis Today, 236, pp. 171-181, 2014.

[6] Gielen, G., Final overview of the expected competencies of future nano-electronics engineers. Work Package 1 - Study of future training needs in micro/nano-electronics, 2011, http://cordis.europa.eu/docs/projects/cnect/1/257051/080/deliverables/001-EurodotsD12.pdf

[7] Santandreu-Mascarell, C., Canós-Darós, L. \& Pons-Morera, C., Competencies and skills for future industrial engineers defined in Spanish degrees, Journal of Industrial Engineering and Management, 4(1), pp. 13-30, 2011.

[8] Chryssolouris, G., Mavrikios, D. \& Mourtzis, D., Manufacturing systems: Skills \& competencies for the future, Procedia CIRP, 7, pp. 17-24, 2013.

[9] Burgoyne, J., Hirsh, W. \& Williams, S., The Development of Management and Leadership Capability and its Contribution to Performance: The evidence, the prospects and the research need. Lancaster University Report, 2004, http://webarchive.nationalarchives.gov.uk/20130401151715/http://www.education.go v.uk/publications/eOrderingDownload/RR560.pdf.

[10] Mudambi, R. \& Swift, T., Proactive R\&D management and firm growth: A punctuated equilibrium model, Research Policy, 40(3), pp. 429-440, 2011.

[11] Torjman, L., Labs: Designing the Future, 2012, https://www.marsdd.com/wpcontent/uploads/2012/02/MaRSReport-Labs-designing-the-future_2012.pdf.

[12] Gitelman, L.D., Gavrilova, T.B., Gitelman, L.M. \& Kozhevnikov, M.V., Proactive management in the power industry: Tool support, International Journal of Sustainable Development and Planning, 12(8), pp. 1359-1369, 2017.

[13] Mueller, M., Bono, B., Pillsbury, S. \& Misthal, B., 2017, Industrial Manufacturing Trends. New operating models, aggressive hiring, smart partnerships, and targeted investments, https://www.strategyand.pwc.com/media/file/2017-Industrial-Manufacturing-Trends.pdf.

[14] Gawer, A., Bridging differing perspectives on technological platforms: Toward an integrative framework, Research Policy, 7(43), pp. 1239-1249, 2014.

[15] Sendogdu, A. \& Diken, A.A., Research on the problems encountered in the collaboration between university and industry, Social and Behavioral Science. Proceedings of 9th International Strategic Management Conference, 99, pp. 966-975, 2013.

[16] Gitelman, L.D., Sandler, D.G., Gavrilova, T.B., \& Kozhevnikov, M.V., Complex Systems management competency for technology modernization, International Journal of Design \& Nature and Ecodynamics, 12(4), pp. 525-537, 2017.

[17] Methodology of innovative management education, ed. Gitelman, L.D. \& Isayev, A.P., Ekonomika Publishing House: Moscow, 2015.

[18] Gitelman, L.D., Kozhevnikov, M.V. \& Sandler, D.G., Technology platforms as a tool for solving complex innovation problems, International Journal of Design \& Nature and Ecodynamics, 11(4), pp. 584-592, 2016. 
[19] Gitelman L.D., Sandler D.G. \& Kozhevnikov M.V., University technology platform of anticipatory learning, Economy of Region, 1, pp. 257-266, 2016.

[20] Abdullah, M.F.A. \& Alias, Ir.A.J., University-Industry Smart Partnership in Enhancing Aviation Technology Education, Proceedings of the 2005 Regional Conference on Engineering Education, pp. 437-439. http://tree.utm.my/wp-content/uploads/2013/02/PRTMohd-Fakhrulrazi-A-Abdullah-Ahmad-Jais-Alias_ok.pdf.

[21] Othman, R. \& Omar, A.F., University and industry collaboration: towards a successful and sustainable partnership, Procedia - Social and Behavioral Sciences, 31, pp. 575579, 2012.

[22] Zainuddin, Z.A.A., Hashim, A.S. \& Aziz, Ir.G.A., Smart tri-partite partnership: polytechnic-industry-student. Procedia - Social and Behavioral Sciences, 31, pp. 517$521,2012$.

[23] Ofek, Y., Evaluating social exclusion interventions in university-community partnerships, Evaluation and Program Planning, 60, pp. 46-55, 2017.

[24] Gitelman, L.D. \& Kozhevnikov, M.V., Management consulting for technological modernization and industry of the future, [in Russian], Economy of Region, 13(1), pp. 204-215, 2017. 